\title{
Results of mass overdose of homeopathic medicines in United Kingdom: scepticism or prejudice?
}

\author{
Marcus Zulian Teixeira
}

School of Medicine of the University of São Paulo (FMUSP), São Paulo, Brazil

Sir,

As recently reported in several newspapers around the world [1], at 10:23 a.m. of January 30, 2010, hundreds of sceptics took p.o. an overdose of homeopathic medicines in front of Boots stores around Britain (Birmingham, Bristol, Brighton, Edinburgh, Glasgow, Hampshire, Leeds, Leicester, London, Liverpool, Manchester, Oxford and Sheffield) to protest against the chain's continuing sale of homeopathic remedies, and to prove that such substances have no scientific basis. Similar events will also be held in Canada and Australia.

Coordinated by Merseyside Skeptics Society, a non-profit organization dedicated to "developing and supporting the sceptical community", the protesters swallowed the contents of entire bottles of homeopathic pills to illustrate their claims that such remedies "are nothing but sugar pills".

Based on the alleged fact that no adverse events were reported after this "mass homeopathic pathogenetic experimentation", they concluded that homeopathic medicines have no activity whatsoever on the human body but function as a placebo [2].

The "homeopathic pathogenetic experimentation" is an excellent method to validate the homeopathic hypotheses, provided the experimenters agree to observe and record without preconceptions the changes in their state of health triggered by homeopathically prepared substances (i.e., diluted and agitated).

For this reason, regarding this episode and its alleged results I wonder whether these self-styled "skeptics" were actually ready to report any change in their state of health observed after the self- experimentation. Most probably the answer is "no", therefore, I suggest that they should rename themselves "prejudiced", because they lack real "scientific spirit", i.e. the one that requires to suspend personal opinions and ideas when searching for the answers to investigation questions.

My assumption is based on the observed results of the project "Homeopathic pathogenetic experimentation as a didatic method" that we have been carrying out since 2003 with students attending the elective discipline "Foundations of Homeopathy" [3] at the School of Medicine of University of São Paulo (FMUSP).

In this scientific protocol (approved by the Ethics Committee for Analysis of Research Projects of the Hospital das Clínicas of FMUSP; randomized, double-blind and placebo-controlled; single doses of known homeopathic medicines in $30 \mathrm{cH}$; critical evaluation of the observed symptoms etc.), through self-experimentation the medical students confirm several symptoms described in previous pathogenetic experimentations, thus corroborating the hypothesis stating that the "information" contained in homeopathic medicines can produce 
pathogenetic effects in human systems, which is a major obstacle for the quantitative-minded to admit homeopathy.

The quali-quantitative experience abovementioned is described in detail in the paper "Brief homeopathic pathogenetic experimentation: a unique educational tool in Brazil", recently published in Evidence-based Complementary and Alternative Medicine (eCAM) [4].

I insist, the chief requirement of the homeopathic method is that observers keep an open and unbiased mind to possible phenomena emerging both in research and therapeutics. Otherwise, they are "pearls before swine".

References

[1] Jones S. Homeopathy protesters to take 'mass overdose' outside Boots. Guardian.co.uk, London, 29 January 2010, Life \& style. Available from: http://www.guardian.co.uk/lifeandstyle/2010/jan/29/scepticshomeopathy-mass-overdose-boots.

[2] Freeman H. Me and my homeopathic overdose. The Guardian, London, 3 February 2010, Comment is free. Available from: http://www.guardian.co.uk/commentisfree/2010/feb/03/homeopathy-overdose-hadley-freeman.

[3] School of Medicine of the University of São Paulo (FMUSP). Elective discipline "Foundations of Homeopathy" (MCM0773). Available from:

http://sistemas2.usp.br/jupiterweb/obterDisciplina?sgldis=mcm0773\&nomdis.

[4] Teixeira MZ. Brief homeopathic pathogenetic experimentation: a unique educational tool in Brazil. Evid Based Complement Alternat Med. 2009; 6(3): 407-414. Available from:

http://ecam.oxfordjournals.org/cgi/reprint/6/3/407?ijkey=V1P04KKdznHcfvB\&keytype=ref.

\section{(c)) BY-NC-ND Licensed to GIRI}

Correspondence author: Marcus Zulian Teixeira, marcus@homeozulian.med.br, www.homeozulian.med.br

How to cite this article: Teixeira MZ. Results of mass overdose of homeopathic medicines in United Kingdom: scepticism or prejudice? [Letter to the Editor]. Int J High Dilution Res. 2010 [cited YYYY Month dd]; 9(30):3-4. Available from: http://www.feg.unesp.br/ ojs/index.php/ijhdr/article/view/374/412 